\title{
Atuação da Psicologia Escolar em Universidade: Diálogos com a Psicologia
}

\section{Comunitária}

\author{
Lígia Carvalho Libâneo* \\ Universidade de Brasília - UnB, Brasília, DF, Brasil \\ ORCID: https://orcid.org/0000-0002-9048-1252 \\ Lúcia Helena Cavasin Zabotto Pulino** \\ Universidade de Brasília - UnB, Brasília, DF, Brasil \\ ORCID: https://orcid.org/0000-0002-4701-2872
}

\section{RESUMO}

Esse estudo teórico busca tecer um diálogo entre aspectos históricos e teórico-metodológicos da psicologia escolar e da psicologia comunitária latino-americana, que acreditamos contribuírem na construção de uma práxis transformadora da psicologia escolar na e com a comunidade universitária. Por meio de um resgate histórico das concepções e práticas da psicologia escolar e da psicologia comunitária latino-americana, tecemos críticas às práticas individualizantes e adaptacionistas da psicologia, refletimos sobre a ação profissional comprometida com a transformação das situações de opressão e de desigualdade social e ressaltamos a importante influência dos movimentos sociais e da educação popular de Paulo Freire na concepção de educação emancipadora. Também discutimos as metodologias inventivas e participativas do psicólogo ligado às práticas de aprofundamento da consciência dos sujeitos da comunidade em relação ao seu modo de vida, bem como a imbricada relação entre transformação social, encontro e afeto. Outras possibilidades de encontro que destacamos são o reconhecimento das potências humanas, a busca pela constituição de uma sociabilidade contra-hegemônica e a participação de todos nesse modus de ser e fazer psicologia escolar atrelando teoria, prática e transformação social.

Palavras-chave: psicologia escolar, psicologia comunitária latino-americana, universidade, práxis.

\section{Performance of School Psychology in University: Dialogues with}

\section{Community Psychology}

\begin{abstract}
This theoretical study seeks to establish a dialogue between historical, theoretical and methodological aspects of school psychology and Latin American community psychology, which we believe that contributes to a proposal to build a transformative praxis of school psychology in and with the university community. Through a historical recover of the
\end{abstract}

ISSN $1808-4281$

v. 21

n. 1


concepts and practices of school psychology and Latin American community psychology, we criticize the individualizing and adaptive practices of psychology, reflect on the professional action committed to the transformation of oppression situations and social inequality and we emphasize the important influence of social movements and Paulo Freire's popular education on the concept of emancipatory education. We also discussed the inventive and participatory methodologies of the psychologist linked to the practices of deepening the awareness of the subjects of the community in relation to their way of life, as well as the interwoven relationship between social transformation, meeting and affection. Other meeting possibilities that we highlight are the recognition of human powers, the search for the constitution of a counter hegemonic sociability in the institution and the participation of all in this modus of being and doing school psychology linking theory, practice and social transformation.

Keywords: school psychology, Latin American community psychology, university, praxis.

\section{Actuación de la Psicología Escolar en Universidad: Diálogos con la}

\section{Psicología Comunitaria}

\section{RESUMEN}

Este estudio teórico busca tejer un diálogo entre los aspectos históricos, teóricos y metodológicos de la psicología escolar y la psicología comunitaria latinoamericana, que creemos contribuir con una propuesta de construcción de una praxis transformadora de la psicología escolar en y con la comunidad universitaria. A través de un rescate histórico de los conceptos y prácticas de la psicología escolar y la psicología comunitaria latinoamericana, criticamos las prácticas individualizadoras y adaptativas de la psicología, reflexionamos sobre la acción profesional comprometida con la transformación de situaciones de opresión y desigualdad social y enfatizamos la importante influencia de los movimientos sociales y la educación popular de Paulo Freire en el concepto de educación emancipadora. También discutimos las metodologías inventivas y participativas del psicólogo vinculadas a las prácticas de profundización de la conciencia de los sujetos de la comunidad en relación a su forma de vida, así como la relación entrelazada entre transformación social, encuentro y afecto. Otras posibilidades de encuentro que destacamos son el reconocimiento de las potencias humanas, la búsqueda por la constitución de una sociabilidad contra hegemónica y la participación de todos en este modo de ser y hacer psicología escolar que vincula teoría, práctica y transformación social.

Palabras clave: psicología escolar, psicología comunitaria latinoamericana, universidad, praxis.

As tentativas de aproximações entre psicologia escolar e psicologia comunitária surgiram da necessidade de construção teórico-metodológica de novos saberes e fazeres em psicologia escolar, mais condizentes com a complexidade de nossa realidade 
socioinstitucional, uma universidade pública brasileira. Nossa atuação profissional política e socialmente referenciada nos coloca na resistência ao modus operandi da psicologia escolar tradicional, que normatiza as questões educacionais e toma a universidade como instituição dada, prestigiando intervenções psicológicas individuais. Essa resistência ativa nos proporciona uma compreensão e uma práxis mais coletiva na universidade em construção, e nos move no sentido de participarmos de seus processos instituintes e de sua constante transformação.

A utilização do termo "comunidade universitária" em documentos oficiais de nossa instituição, a Universidade de Brasília (UnB), e em nomenclaturas como Decanato de Assuntos Comunitários, Centro Comunitário, e em produções acadêmicas sobre educação superior (Morosini, 2009; Santos, 2010; Sousa, 2010) também nos levou ao estudo da psicologia comunitária. Nossa expectativa inicial com esses estudos era de nos instrumentalizarmos com concepções e metodologias de ação, em um esforço de ampliar a compreensão da instituição. Partindo do materialismo histórico-dialético, segundo o qual a realidade é quem busca os conceitos (Nepomuceno, Ximenes, Cidade, Mendonça, \& Soares, 2008), iniciamos alguns estudos mais aprofundados sobre a psicologia comunitária, contextualizando-os à nossa realidade.

Sabemos que muitas vezes a perspectiva de comunidade trabalhada por autores da psicologia comunitária envolve a experiência de moradia dos sujeitos comunitários. Embora haja moradia estudantil e residência funcional em alguns campi universitários, essa experiência não contempla todos os atores da comunidade universitária. Apesar dessa importante diferença, ao assumirmos a universidade como um território existencial para seus atores, já que constituinte de suas subjetividades, de seus papeis sociais e profissionais, entendemos ser possível e interessante tecer um diálogo entre contribuições teóricometodológicas da psicologia escolar e da psicologia comunitária.

Pensamos que um primeiro ponto de contato entre a psicologia escolar e a psicologia comunitária é a história de consolidação das duas áreas no Brasil. Os dois campos apresentam em comum a problematização da vertente psicologizante da psicologia, bem representada na citação de Martín-Baró, a qual está presente no artigo de Nepomuceno et al. (2008)

Los problemas sociales se convierten así en problemas de personas, y los problemas políticos en problemas de caracteres o personalidades. Se incurre en el personalismo a todos los niveles, tanto para el éxito como, sobre todo, para el fracaso [...] De este modo las soluciones sociales y políticas recomendadas por este tipo de análisis tienden 
siempre a asumir como intocable el sistema social establecido y a estimular a los individuos a plegarse a sus exigencias. (Martín-Baró como citado em Nepomuceno et al., 2008, pp. 459)

A psicologia, enquanto ciência e profissão, que muitas vezes serviu, e ainda serve, como instrumento útil para a reprodução do sistema, por meio de enfoque individualizante e subjetivista, deve buscar, de acordo com Martín Baró (1996), "a desalienação das pessoas e grupos", ajudando-as "a chegar a um saber crítico sobre si próprias e sobre sua realidade" (p. 17). O autor salvadorenho faz uma reflexão importante sobre a necessária formulação de perguntas críticas pelos psicólogos a respeito do caráter de sua atividade e, portanto, a respeito do papel que desempenha na sociedade. Segundo ele, os psicólogos não devem centrar-se tanto no onde, mas no a partir de quem; não tanto em como se está realizando algo, quanto em beneficio de quem; e, assim, não tanto sobre o tipo de atividade que se pratica (clínica, escolar, industrial, comunitária ou outra), mas sobre quais são as consequências históricas concretas que essa atividade está produzindo. (p. 22)

Assumindo a pertinência da crítica de Martín-Baró, queremos, aqui, contextualizá-la no campo da educação. A atuação em psicologia escolar tem sido muito criticada por estar vinculada à reprodução de práticas que individualizam nos sujeitos, especialmente estudantes e familiares, questões pertinentes ao processo educativo e à conjuntura político-social (Angelucci, Kalmus, Paparelli, \& Patto, 2004; Barbosa, 2012; Marinho-Araujo, 2016a; Marinho-Araujo \& Almeida, 2005; Maroldi, 2012; Meira, 2012; Patto, 1990; Souza, 2009). A história da psicologia escolar é marcada por atuações ligadas a um tratamento individual das queixas escolares, sendo vasta a literatura da psicologia escolar que reporta e critica as intervenções promotoras de ajustamento dos estudantes à realidade escolar (Meira, 2012; Patto, 1990; Souza, 2009). Essas práticas individualizantes e adaptacionistas da psicologia podem contribuir com processos subjetivos que sustentam e viabilizam os mecanismos socioeconômicos da injustiça social, conforme alerta Martín-Baró (1996).

A partir das décadas de 1970 e 1980, emergiram vozes de dentro da psicologia que questionavam "a serviço de quem” estava colocado o saber psicológico (Martín-Baró, 1996), reflexões essas que possibilitaram a construção e a consolidação da psicologia escolar crítica. Barbosa (2012) denomina "O período da crítica" (1981-1990) como um momento de grande relevância para a área de psicologia escolar, o qual se caracterizou pela contextualização social e política na compreensão das questões e queixas escolares com vistas à promoção do desenvolvimento de práticas educativas de melhor qualidade. 
A partir do período da crítica, o fracasso escolar, tradicionalmente visto apenas pelo prisma da culpabilização das crianças e de seus pais ou professores, por problemas psicossociais ou técnicos, respectivamente, passa então a ser questionado pelos vieses institucional e político (Angelucci et al., 2004). Com essa leitura mais ampliada do fracasso escolar, a psicologia passa a colocar no cerne da compreensão desse fenômeno, portanto, da discussão do papel da escola como organização social que pode contribuir para a construção da emancipação ou, em contraponto, para a alienação dos sujeitos e da sociedade.

Fenômeno semelhante de contextualização político-social à atuação do profissional de psicologia acontece no campo da psicologia comunitária. De acordo com Sawaia (2013), na discussão sobre a psicologia comunitária é preciso estabelecer uma diferenciação importante entre os compromissos epistemológicos, políticos e ideológicos da psicologia comunitária norte-americana e os da psicologia latino-americana. A primeira baliza-se em uma compreensão de comunidade como unidade consensual, sujeito único e homogêneo, lugar de gerenciamento de conflitos. Nessa direção, a atuação do psicólogo estaria voltada para a união de esforços entre povo e autoridades governamentais, tendo em vista a melhoria das condições de vida da comunidade. Para Sawaia (2013), trata-se de uma concepção acoplada a um projeto de modernização dos setores atrasados e pobres, visando adaptação ao capitalismo avançado. Por outro lado, a psicologia comunitária latino-americana é apresentada pela autora como possibilidade de transformação de uma sociedade exploradora.

A origem da psicologia comunitária na América Latina, segundo Lima e Bomfim (2012), está ligada à luta popular dos movimentos sociais, com destaque para o movimento de saúde mental. De acordo com as autoras, esse movimento buscava a modificação da perspectiva de saúde curativa para a de uma ação preventiva e promotora de qualidade de vida, enfatizando a comunidade como construtora de saúde mental.

Compondo o quadro de influências históricas no campo da psicologia comunitária na América Latina, Lane (2013) destaca também as práticas de educação popular, realizadas na década de 1960, com a alfabetização de adultos como instrumento de conscientização, a partir dos trabalhos de Paulo Freire e outros, práticas das quais também participavam psicólogos. Na década de 1970, inspirados por essas práticas, psicólogos desenvolveram atividades em comunidades tendo como meta a conscientização da população.

A prática da educação popular realizada por Paulo Freire também é um ponto de contato entre autores da psicologia escolar e da psicologia comunitária. Uma discussão central de sua teoria é a contraposição entre educação bancária e educação transformadora. Esse autor nomeia por educação bancária a prática educativa que serve à dominação, que inibe a 
criatividade, que "domestica", que nega os homens na sua vocação ontológica e histórica de humanizar-se (Freire, 1977, p. 75). Por outro lado, na prática problematizadora ou educação emancipadora, os educandos desenvolvem sua compreensão do mundo na relação com ele, como realidade em transformação e em processo. Segundo Guzzo e Euzébios Filho (2005), a educação emancipadora se constitui em um processo coletivo que assume como norte a reflexão acerca da necessidade e da possibilidade de a população oprimida despertar para as tarefas necessárias para a modificação da estrutura social vigente. A proposta de Educação Emancipadora engloba alunos, professores ou quaisquer outras pessoas que optem pela transformação social, que entendam a sociedade sob a perspectiva das tensões expressas pela desigualdade social (p. 46).

Inspiradas na discussão sobre educação bancária ou transformadora, podemos pensar a atuação do psicólogo escolar. Como se caracterizaria uma psicologia escolar bancária em contraposição a uma psicologia escolar transformadora?

Uma psicologia escolar bancária poderia se caracterizar por práticas que corroboram relações opressoras dentro do ambiente escolar, colocando os saberes psicológicos a serviço da manutenção das estruturas de poder. Exemplo disso seria a culpabilização e a responsabilização dos estudantes e de seus pais ou professores pelo fracasso escolar, desconsiderando na análise desse fenômeno os interesses econômicos, políticos e sociais que marcam uma sociedade de classes. Para tanto, o psicólogo assumiria um olhar de normatização de processos de desenvolvimento, classificando esses processos, e realizando práticas de ajustamento e adequação aos padrões normativos vigentes na escola. $\mathrm{O}$ profissional lançaria mão de um saber-poder que colocaria os membros da comunidade escolar no lugar de objetos de sua intervenção.

A perspectiva transformadora, por outro lado, poderia se fundamentar na compreensão da escola como forma de organização social potente para o desenvolvimento, a transformação e a emancipação humana dos discentes, e assumiria como prerrogativa formas de trabalho mais libertadoras no contexto educativo também para docentes e demais profissionais da educação, inclusive para o próprio psicólogo escolar. No caso do chamado fracasso escolar, este seria compreendido em toda a sua complexidade, considerando a sua dimensão histórica, social, ética, política, afetiva, pedagógica, envolvendo todos os atores da comunidade educacional.

Uma psicologia comprometida com a transformação, que se proponha a enfrentar as problemáticas da educação, em sua complexidade, consideraria os membros da comunidade como atores do processo educativo. Assim, os sujeitos da comunidade deixariam de ser 
objetos de estudo e de intervenção desenvolvidos pelo psicólogo e passariam a ser agentes participantes da construção dessa práxis.

Essa perspectiva de sujeito ativo e protagonista, que se constitui nas relações sociais em comunidade, é fortemente assumida na psicologia comunitária. Guareschi (2013) parte da conceituação de comunidade em Marx como um tipo de vida em sociedade "onde todos são chamados pelo nome" para afirmar a comunidade como "uma vivência em sociedade onde a pessoa, além de possuir um nome próprio, isto é, além de manter sua identidade e singularidade, tem possibilidade de participar, de dizer sua opinião, de manifestar seu pensamento, de ser alguém" (p. 78). Lima e Bomfim (2012) afirmam a consciência transitiva como ligada ao aprofundamento da consciência dos moradores em relação ao seu modo de vida, deflagrando o desenvolvimento do sujeito comunitário e da comunidade.

Nessa direção, admitimos a conscientização como o que fazer (Martín-Baró, 1996) do psicólogo como outro aspecto de aproximação entre os campos da psicologia escolar e da psicologia comunitária. Enquanto o psicólogo comunitário é um analista-facilitador (Lima \& Bomfim, 2012) de reflexão da relação entre os modos de vida na comunidade e o desenvolvimento de seus moradores, o psicólogo escolar pode pensar na construção de espaços de reflexão junto a membros da comunidade acadêmica sobre o modo de vida na universidade, os quais marcam nossa construção-produção de subjetividade. Discorrendo sobre os caminhos da intervenção do psicólogo escolar, Marinho-Araujo (2016a) defende que estes devem

estar ancorados na potencialidade de situações sociais de desenvolvimento (Vygotsky, 1999, 2000a) as quais oportunizem vivências que engendrem, de forma interdependente, ressignificações e circulação de sentidos na constituição subjetiva dos sujeitos em suas relações históricas e culturais, gerando, dialeticamente, processos de conscientização nos tempos e espaços de aprendizagens. (Marinho-Araujo, 2016a, pp. 53)

$\mathrm{Na}$ atuação do psicólogo comunitário, Montero (2006) afirma que o profissional deve ser reconhecido pela comunidade, em que se constroem confiança e respeito mutuamente. A relação deve ser pautada na horizontalidade (Lima \& Bomfim, 2012), onde o psicólogo tem seus conhecimentos científicos, seus estudos, sua práxis e a comunidade tem sua dinâmica, valores, concepções (Freitas, 1998). Nessa relação, Gois (2005) afirma que 
O sentido do desenvolvimento e o controle da ação devem ser da comunidade ou, pelo menos, definidos e compartilhados de comum acordo. Isso implica um desenvolvimento participativo, autossustentável, de busca de autonomia local, de interdependência, e não de dependência ao exterior da comunidade. (Gois, 2005, pp. 66)

Lima e Bomfim (2012) destacam que é fundamental que a comunidade se responsabilize, aproprie-se do processo e possa construir com o profissional. Nesse sentido, Lane (2013) destaca o papel do grupo como condição para o conhecimento da realidade comum, para a autorreflexão e para a ação conjunta e organizada. Guareschi (2013) também ressalta a importância da garantia de autonomia e autogestão das próprias comunidades. Segundo ele, "a autogestão é o ápice de relações genuinamente democráticas, onde há participação de todos" (p. 81).

Para a inserção na comunidade, Freitas (1998) apresenta alguns instrumentos, como entrevistas (individuais e coletivas), registros em diários de campo, pesquisa documental, recuperação da história do lugar, conversas informais (bares, calçada, mercados, padarias...), caminhadas pela rua, participação em reuniões comunitárias, visitas a casas, a festas ou a eventos da comunidade. Os instrumentos, no entanto, são construídos de acordo com a necessidade do local e dos fatores políticos, históricos, pessoais e ambientais, sempre considerando a potencialidade das metodologias participativas (Lima \& Bomfim, 2012).

Lima e Bomfim (2012) apresentam o mapeamento psicossocial como uma metodologia de facilitação comunitária com o objetivo de "conhecer a realidade a partir da caminhada, em que proporcionam o reconhecimento da história da comunidade, das atividades, dos significados e dos sentimentos dos moradores em relação ao lugar onde vivem” (p. 680). Gois (2008) apresenta o andar pela comunidade para além do simplesmente passar pelos lugares, "é olhar para cada ponto, cada lugar, cada morador, cada situação que se apresenta no local de andança, com olhar sensível e perceptível" (p. 197).

No mapeamento psicossocial, Lima e Bomfim (2012) ressaltam a importância de se conhecer a maneira como os moradores se vinculam ao lugar e às pessoas, o fortalecimento de laços afetivos, as atividades de produção e de lazer, os estilos de vida, os hábitos, os potenciais e os problemas do cotidiano, as estruturas e organizações sociais, entre outros. Para as autoras, as metodologias de facilitação, a exemplo do mapeamento psicossocial, possibilitam a troca de saberes, popular e científico, o conhecimento e compreensão das 
atividades comunitárias e das problemáticas e dos potenciais a serem desenvolvidos, a consciência transitiva.

Assim como a psicologia comunitária trabalha com metodologias participativas, que privilegiam a troca de saberes, a participação, a autonomia e a autogestão, também, nós, psicólogos escolares, nos colocamos em lugares de construção coletiva, respeitando os saberes e fazeres dos demais atores, e esperançosos na potencialidade dos encontros, a exemplo dos trabalhos de Chagas e Pedroza (2013), Facci e Souza (2011), Marinho-Araujo (2014), Mitjáns Martinez (2009), Pulino (2001), Sant’Ana e Guzzo (2016), Sampaio (2010), Souza, Petroni, Dugnani, Barbosa e Andrada (2014). Para Sawaia (2006), a potência de vida é aumentada ou diminuída nos encontros com outros corpos e outras mentes. Segundo ela, “o sujeito é uma potencialidade em ato, cuja realização se dá, exclusivamente, nos encontros (experiências), pois o homem não é causa de si, ao contrário, é da natureza do corpo e da alma ser afetado e afetar" (p. 86). Sawaia (2006) baseia-se na produção do filósofo Espinosa, segundo o qual os afetos podem aumentar ou diminuir as potências dos corpos, segundo leis complexas. Para Domingues e Franco (2014),

Quando um corpo encontra outro corpo em uma relação de composição (bons encontros), produzem-se afetos que aumentam a potência de ação dos corpos. Em outra situação, quando temos um encontro com um corpo que o decompõe (maus encontros), isto é, que ameaçam a nossa existência, produzem-se afetos que diminuem nossa potência de ação. (Domingues \& Franco, 2014, pp. 25)

Importante destacar que, segundo Sawaia (2006), a força de expandir a vida é aumentada e diminuída nos encontros, e não consequência de um amadurecimento natural. A autora afirma que "o bloqueio dos encontros e da sensibilidade é a principal estratégia de captura e disciplinarização dos processos de subjetivação pelas forças sociais”, uma vez que as "relações autoritárias e excludentes precisam inibir a imaginação, a sensibilidade estética, e bloquear os afetos, instalando uma política de cristalização da capacidade de afetar e ser afetado, para reproduzir-se” (p. 91). Por outro lado, os encontros e as sensibilidades oferecem juntos "a base para a explicação da possibilidade de fuga da captura tanto das leis da natureza quanto das leis culturais" (Sawaia, 2006, p. 91), isto é, liberdade e criação são condições da expansão da potência de ação. Essas conceituações da autora nos demonstram que não há ética e transformação social independentes dos afetos. 
Reconhecendo a potência dos encontros, é preciso assumir também uma disponibilidade para que eles aconteçam. Na psicologia escolar, a presença do profissional no cotidiano da instituição abre a possibilidade de encontros e transformações. Uma possibilidade de presença no cotidiano acadêmico seria por meio de caminhadas.

Acreditamos que a caminhada é muito mais do que simplesmente passar pelos lugares, é olhar para cada pessoa, cada lugar e cada situação que se apresenta no local de andança, com olhar sensível e disponível (Gonçalves, 2008). As caminhadas podem constituir-se como construções poéticas de resistência cotidiana, de modos de fazer, de maneiras de viver o real estando presente, do olhar que desenha a própria paisagem, da disciplina dos pés, que amplia o olhar (Gonçalves, 2008).

Farrero (2014) apresenta a Pedagogia do Caminhar como uma proposta educativa na qual convergem a ação de caminhar e a formação (Farrero, 2014). Ele defende o caminhar como algo mais que deslocamento e atividade física, pois pode suscitar outras experiências como inspirações literárias, espiritualidade, vivências estéticas, comprovações científicas, descobertas artísticas reveladoras, autoconhecimento, desobediência civil e outros. O caminhar estaria, segundo ele, ligado a uma prática de autoria "una forma de hacer camino y de (auto) formarse" (p. 188). Inspiradas nessa teorização, pensamos o caminhar como prática inventiva do psicólogo escolar, ao mesmo tempo interventiva e autoformativa. Com olhos despertos, podemos reconhecer e valorizar a existência e a resistência de "outros corpos, outros espaços, outros olhares, outras sensibilidades" (Zanella, 2006, p. 146) na universidade.

Tanto na psicologia escolar crítica (Carvalho, Santos \& Sampaio, 2015; Matos, Santos, \& Dazzani, 2016; Moreira \& Guzzo, 2016; Patto, 1990; Sampaio, 2010) como na psicologia comunitária (Góis, 2005, 2008; Gonçalves \& Portugal, 2016; Lane, 2013; Nepomuceno et al., 2008), diversos autores valorizam a originalidade e a diversidade dos povos latino-americanos, criticam a importação de teorias e métodos psicológicos desenvolvidos em um contexto histórico-cultural diferente da realidade desses povos, e privilegiam uma ação profissional comprometida com a transformação das situações de opressão e desigualdades sociais. Sampaio (2010) discute que a garantia de reservas de vagas para estudantes oriundos de escolas públicas, negros, afrodescendentes, quilombolas e indígenas construiu desafios contemporâneos para a atuação do psicólogo escolar. Defende como prática deste profissional o suporte efetivo a todos os estudantes de origem das camadas populares que ingressam nas universidades brasileiras, via políticas de ações afirmativas, especialmente nos anos letivos iniciais. Ela propõe também uma "intervenção criativa, modular, suficientemente delicada para adaptar-se a condições diversas" (p. 103), chamando 
atenção para que a vida acadêmica seja pensada não apenas pelo desempenho, mas pelos diversos aspectos afetivos da experiência universitária, envolvendo a sociabilidade e a convivência com os membros da comunidade acadêmica.

A proposição de Sampaio (2010) nos inspira a refletir sobre a força e a potência da participação dos membros da comunidade universitária (estudantes e trabalhadores) na construção de novas formas de sociabilidades, que poderiam contribuir com experiências universitárias libertadoras e emancipadoras para todos os segmentos da comunidade. Nas palavras de Oliveira, Ximenes, Coelho e Silva, (2008) a educação teria um papel fundamental na construção de "novas sociabilidades, mais democráticas e justas, afetivas e solidárias, fortalecendo para tanto as forças progressistas que favoreciam a autonomização, o compromisso social e o vínculo histórico com o anúncio de um novo horizonte de vida social" (p. 151). Nessa mesma direção, Nepomuceno et al. (2008) afirmam que em uma sociabilidade contra-hegemônica, que seria possível mediante uma práxis de libertação, seria relevante "a formação e atuação em coletivos capazes de atuar, em diversas frentes associadas, num movimento instituinte de novos nexos formadores dessa sociabilidade" (p. 462).

No encontro entre a psicologia escolar e a psicologia comunitária, esse artigo buscou refletir sobre a construção de uma psicologia escolar em universidade pautada na intersecção entre teoria, prática e transformação social. Discutimos o quefazer do psicólogo escolar ligado à práxis de libertação, com auxilio de metodologias participativas e mobilizadoras de encontros com os demais membros da comunidade universitária, e pautadas no diálogo, na troca de saberes e construção coletiva de fazeres.

Ressaltamos uma diferenciação importante entre o psicólogo escolar e o psicólogo comunitário, que seria a condição de dentro e de fora da comunidade, respectivamente. Diferentemente do psicólogo comunitário, o psicólogo escolar tem uma vinculação institucional a qual reverbera em seus fazeres e nos olhares que lança sobre a comunidade e que esta lança sobre ele, ao mesmo tempo ele é parte dessa comunidade e tem sua identidade profissional constituída na relação com o local onde é vivido o papel profissional, a universidade. Em momento futuro, gostaríamos de tecer reflexões sobre esse drama de papeis (Silva \& Magiolino, 2016; Vygotsky, 2000) que a psicologia escolar parece ocupar numa práxis em comunidade.

Ainda sobre pesquisas futuras para nós, psicólogos escolares, estudiosos e profissionais, sugerimos a importância da construção de diálogos interdisciplinares, permitindo que a realidade busque os conceitos para nossa ação profissional. O nosso estudo teórico pretendeu discutir fazeres e saberes da psicologia comunitária que pudessem inspirar 
novos olhares, fazeres e saberes da psicologia escolar em universidade. Nessa aproximação, fomos provocados a nos expormos mais à vida comunitária em todos os seus acontecimentos.

Nosso texto se propôs a fazer-se convite para que outras produções apresentem suas metodologias inventivas em psicologia escolar. Inventivas no sentido de privilégio dos encontros e de valorização da autonomia local. Inventivas no sentido de uma experimentação de métodos que circulem e caminhem pela comunidade. Inventivas no sentido de possibilitarem o conhecimento da maneira como os sujeitos comunitários se vinculam ao lugar e às pessoas, fortalecem seus laços afetivos, ensinam e aprendem, realizam suas atividades de produção e de lazer. Inventivas no sentido de reconhecer as dificuldades e também os potenciais da comunidade universitária. Inventivas no sentido de pensar e refletir sobre a construção de tempos e espaços educativos na universidade, que sejam verdadeiros espaços de acolhimento e pertencimento para todos os públicos.

Para não encerrar nossas reflexões sobre possibilidades de encontro entre psicologia escolar em universidade e psicologia comunitária, admitimos a importância da discussão das dimensões do inacabamento (Freire, 2002) e da criação na experiência humana. De acordo com Pulino (2016), “criando lugares abertos a novas possibilidades, abertos ao afeto, ao cuidado mútuo" (p. 94), "estaremos confirmando nossa condição de seres que nos construímos ao montarmos o próprio cenário em que se constituem” (pp. 93-94). Para tanto, necessitamos (re)conhecer a universidade e a comunidade universitária em suas contradições, como espaço/tempo (Pulino, 2007) de criação, resistência e potência.

Esperamos que, por meio desse artigo, os saberes da psicologia comunitária com os quais dialogamos possam inspirar novos olhares, fazeres e saberes da psicologia escolar em universidade. Que ele possa contribuir especialmente para a valorização da originalidade e da diversidade dos povos latino-americanos que constituem a universidade brasileira, a reflexão junto a membros da comunidade acadêmica sobre nosso modo de vida na universidade, o reconhecimento das potências humanas, a busca pela constituição de uma sociabilidade contra-hegemônica na instituição, e a práxis transformadora da psicologia na e com a comunidade universitária.

\section{Referências}

Angelucci, C. B., Kalmus, J., Paparelli, R., \& Patto, M. H. S. (2004). O estado da arte da pesquisa sobre o fracasso escolar (1991-2002): Um estudo introdutório. Educação e pesquisa, 30(1), 51-72. doi: 10.1590/S1517-97022004000100004 
Barbosa, D. R. (2012). Contribuições para a construção da historiografia da psicologia educacional e escolar no Brasil. Psicologia: Ciência e Profissão, 32(spe), 104-123. doi: 10.1590/S1414-98932012000500008

Carvalho, A., Santos G. G., \& Sampaio, S. M. R. (2015). Observatório da vida estudantil: Avaliação e qualidade no ensino superior: Formar como e para que mundo?. Salvador: Edufba.

Chagas, J. C., \& Pedroza, R. L. S. (2013). Psicologia Escolar e gestão democrática: Atuação em escolas públicas de educação infantil. Psicologia Escolar e Educacional, 17(1), 35-43. doi: 10.1590/S1413-85572013000100004

Domingues, A. R., \& Franco, E. M. (2014). Reflexões teóricas sobre sujeitos coletivos e experiências comunitárias. In C. Stella (Org.), Psicologia Comunitária: Contribuições teóricas, encontros e experiências (pp. 15-44). Rio de Janeiro: Vozes.

Farrero, J. G. (2014). Caminar: Experiencias y prácticas formativas. Barcelona: Editorial UOC.

Facci, M. G. D., \& Souza, M. P. R. (2011). “- O que este menino tem?”: Contribuições do método instrumental de Vigotski para o processo de avaliação psicológica. In C. M. Marinho-Araujo \& R. S. L. Guzzo (Orgs.), Psicologia escolar: Identificando e superando barreiras (pp. 77-100). Campinas: Alínea.

Freire, P. (1997). Educação "bancária" e educação libertadora. In M. H. S. Patto (Org.), Introdução à psicologia escolar (pp. 61-78). São Paulo: T. A. Queiroz.

Freire, P. (2002). Pedagogia da Autonomia: Saberes necessários à prática docente. São Paulo: Paz e Terra.

Freitas, M. F. Q. (1998). Inserção na comunidade e análise de necessidades: Reflexões sobre a prática do psicólogo. Psicologia Reflexão e Crítica, 11(1), 175-189. doi: 10.1590/S0102-79721998000100011

Góis, C. W. L. (2005). Psicologia comunitária: Atividade e consciência. Fortaleza: Publicações Instituto Paulo Freire de Estudos Psicossociais.

Góis, C. W. L. (2008). Saúde comunitária: Pensar e fazer. São Paulo: Aderaldo \& Rothschild.

Gonçalves, M. H. (2008). Por uma pedagogia a pé: A caminhada como construção poética (Monografia de especialização). Universidade Federal do Rio Grande do Sul, Porto Alegre, RS, Brasil. Recuperado de http://hdl.handle.net/10183/15683 
Gonçalves, M. A., \& Portugal, F. T. (2016). Análise histórica da psicologia social comunitária no Brasil. Psicologia \& Sociedade, 28(3), 562-571. doi: 10.1590/180703102016v28n3p562

Guareschi, P. (2013). Relações comunitárias: Relações de dominação. In R. H. F. Campos (Org.), Psicologia Social Comunitária: Da solidariedade à autonomia (pp. 66-81). Rio de Janeiro: Vozes.

Guzzo, R. S., \& Euzébios Filho, A. (2005). Desigualdade social e sistema educacional brasileiro: A urgência da educação emancipadora. Escritos de Educação, 4(2), 39-48. Recuperado de http://pepsic.bvsalud.org/scielo.php?script=sci_arttext\&pid=S167798432005000200005

Guzzo, R. S. L., Moreira A. P. G., \& Mezzalira A. S. C. (2011). Avaliação psicossocial: Desafios para a prática profissional nos contextos educativos. Avaliação Psicológica, 10(2), 163-171. Recuperado de http://pepsic.bvsalud.org/scielo.php?script=sci_arttext\&pid=S167704712011000200007

Lane, S. T. M. (2013). Histórico e fundamentos da psicologia comunitária no Brasil. In R. H. F. Campos (Org.), Psicologia Social Comunitária: Da solidariedade à autonomia (pp. 15-28). Rio de Janeiro: Vozes.

Lima, D. A., \& Bomfim, Z. A. C. (2012). Mapeamento psicossocial participativo: Metodologia de facilitação comunitária. Psicologia Argumento, Curitiba, 30(71), 679689. doi: 10.7213/psicol.argum.7474

Marinho-Araujo, C. M. (2016). Inovações em Psicologia Escolar: O contexto da educação superior. Estudos de Psicologia (Campinas), 33(2), 199-211. doi: 10.1590/19820275201600020000

Marinho-Araujo, C. M. (2016). Perspectiva histórico-cultural do desenvolvimento humano: Fundamentos para atuação da psicologia escolar. In M. V. Dazzani, \& V. L. T. Souza (Orgs.), Psicologia escolar crítica: Teoria e práticas de contextos educacionais (pp. 37-55). Campinas: Alínea.

Marinho-Araujo, C. M (2014). Intervenção Institucional: Ampliação crítica e política da atuação em Psicologia Escolar. In R. S. L. Guzzo (Org.), Psicologia Escolar: Desafios e Bastidores na Educação Pública (pp. 153-175). Campinas: Alínea.

Marinho-Araujo, C. M., \& Almeida, S. F. C. (2005). Psicologia escolar: Construção e consolidação da identidade profissional. Campinas: Alínea. 
Maroldi, A. M. (2012). Psicologia Escolar: Um estudo bibliométrico da literatura nacional (1962 - 2011) (Dissertação de mestrado). Universidade Federal de Rondônia, Porto Velho, RO, Brasil. $\quad$ Recuperado de https://www.ri.unir.br/jspui/handle/123456789/2005

Martín-Baró, I. (1996). O papel do psicólogo. Estudos de Psicologia (Natal), 2(1), 7-27. doi: 10.1590/S1413-294X1997000100002

Meira, M. E. M. (2012). Para uma crítica da medicalização na educação. Psicologia Escolar e Educacional, 16(1), 136-142. doi: 10.1590/S1413-85572012000100014

Mitjáns Martinez, A. (2009). Psicologia Escolar e Educacional: Compromissos com a educação brasileira. Psicologia Escolar e Educacional, 13(1), 169-177. Recuperado de http://pepsic.bvsalud.org/scielo.php?script=sci_arttext\&pid=S141385572009000100020

Montero, M. (2006). Hacer para Transformar: El método en la psicologia comunitária. Buenos Aires: Paidós.

Moreira, A. P. G., \& Guzzo, R. S. L. (2016). Situação-limite e potência de ação: Atuação preventiva crítica em psicologia escolar. Estudos de Psicologia (Natal), 21(2), 204215. doi: $10.5935 / 1678-4669.20160020$

Morosini, M. C. (2009). Qualidade na educação superior: Tendências do século. Estudos em avaliação educacional, 20(43), 165-186. doi: 10.18222/eae204320092043

Nepomuceno, L. B., Ximenes, V. M., Cidade, E. C., Mendonça, F., \& Soares, C. A. (2008). Por uma psicologia comunitária como práxis de libertação. Psico, 39(4), 456-464. Recuperado de https://revistaseletronicas.pucrs.br/ojs/index.php/revistapsico/article/view/3532

Matos, A. S., Santos, J. V. B. K., \& Dazzani, M. V. M. (2016). O psicólogo escolar na educação superior: Promovendo um olhar ampliado sobre assistência estudantil. In M. V. Dazzani, \& V. L. T. Souza (Orgs.), Psicologia escolar crítica: Teoria e práticas de contextos educacionais (pp. 115-125). Campinas: Alínea.

Oliveira, F. P., Ximenes, V. M., Coelho, J. P. L., \& Silva, K. S. (2008). Psicologia comunitária e educação libertadora. Psicologia: Teoria e Prática, 10(2), 147-161. Recuperado de http://pepsic.bvsalud.org/scielo.php?script=sci_arttext\&pid=S151636872008000200012

Patto, M. H. S. (1990). A produção do fracasso escolar: Histórias de submissão e rebeldia. São Paulo: T. A. Queiroz. 
Pulino, L. H. C. Z. (2001). Acolher a criança, educar a criança: Uma reflexão. Em Aberto, 18(73), 29-40. doi: 10.24109/2176-6673.emaberto.18i73.2134

Pulino, L. H. C. Z. (2007). Espaço Aion: A Filosofia como espaço de reflexão na comunidade. Childhood \& Philosophy, 3(5), 155-167. Recuperado de https://www.redalyc.org/articulo.oa?id=512051706010

Pulino, L. H. C. Z. (2016). Lugares de Infância: Tempo de encontro. In S. Barbato \& M. F. F. Cavaton (Orgs.), Desenvolvimento humano e educação: Contribuições para a educação infantil e o primeiro ano do ensino fundamental (pp. 71-96). Aracaju: Edunit.

Sampaio, S. M. R. (2010). A Psicologia na educação superior: Ausências e percalços. Em Aberto, 23(83), 95-105. doi: 10.24109/2176-6673.emaberto.23i83.2253

Sant'Ana, I. M., \& Guzzo, R. S. L. (2016). Psicologia escolar e projeto político-pedagógico: Análise de uma experiência. Psicologia \& Sociedade, 28(1), 194-204. doi: 10.1590/1807-03102015aop004

Santos, B. S. (2010). A universidade no século XXI: Para uma reforma democrática e emancipatória da universidade. São Paulo: Cortez.

Sawaia, B. B. (2006). Introduzindo a afetividade na reflexão sobre estética, imaginação e constituição do sujeito. In S. Z. Da Ros, K. Maheirie \& A. V. Zanella (Orgs.), Relações estéticas, atividade criadora e imaginação: Sujeitos e (em) experiência (pp. 85-94). Florianópolis: NUP/CED/UFSC.

Sawaia, B. B. (2013). Comunidade: A apropriação científica de um conceito tão antigo quanto a humanidade. In R. H. F. Campos (Org.), Psicologia social comunitária: Da solidariedade à autonomia (pp. 35-53). Petrópolis, RJ: Vozes.

Silva, D. N. H., \& Magiolino, L. L. S. (2016). Dimensões (est) éticas e políticas da paixão entre Simone e Nelson. Psicologia \& sociedade, 28(1), 45-54. doi: 10.1590/1807$03102015 \mathrm{v} 28 \mathrm{n} 1 \mathrm{p} 045$

Sousa, S. B. (2010). A 'comunidade académica' como um conceito errático. Sociologia: Revista do Departamento de Sociologia da FLUP, 20, 149-166. Recuperado de http://ojs.letras.up.pt/index.php/Sociologia/article/download/2283/2090

Souza, M. P. R. (2009). Psicologia Escolar e Educacional em busca de novas perspectivas. Psicologia Escolar e Educacional, 13(1), 179-182. Recuperado de http://pepsic.bvsalud.org/scielo.php?script=sci_arttext\&pid=S141385572009000100021 
Souza, V. L. T., Petroni, A. P., Dugnani, L. A. C., Barbosa, E. T., \& Andrada, P. C. (2014). O psicólogo na escola e com a escola: A parceria como forma de atuação promotora de mudanças. In Guzzo, R. S. L. (Org.), Psicologia Escolar: Desafios e bastidores na educação pública (pp. 27-54). Campinas: Alínea.

Vygotsky, L. S. (2000). Manuscrito de 1929. Educação \& Sociedade, 21(71), 21-44. Recuperado de https://www.scielo.br/pdf/es/v21n71/a02v2171.pdf

Zanella, A. V. (2006). Sobre olhos, olhares e seu processo de (re)produção. In L. H. C.. Lenzi, S. Z. Da Ros, A. M. A. Souza, \& M. M. Gonçalves (Orgs.), Imagem: Intervenção e pesquisa (pp. 139-150). Florianópolis: NUP/CED/UFSC.

\section{Endereço para correspondência}

\section{Lígia Carvalho Libâneo}

SGAN 911, bloco B apto 19, Condomínio Green Park, Asa Norte, Brasília - DF, Brasil. CEP 70790-110

Endereço eletrônico: ligialibaneo@gmail.com

\section{Lúcia Helena Cavasin Zabotto Pulino}

Universidade de Brasília - UnB

Campus Universitário Darcy Ribeiro

Colina, bloco E apto 106, Asa Norte, Brasília - DF, Brasil. CEP 70904-105

Endereço eletrônico: luciahelenaczp@ gmail.com

Recebido em: 15/07/2019

Reformulado em: 05/08/2020

Aceito em: 17/08/2020

\footnotetext{
Notas

* Psicóloga escolar na Universidade de Brasília. Psicóloga escolar da Coordenação de Articulação da Comunidade Educativa - CoEduca/ DASU/ DAC/ UnB. Doutora pelo PGPDS/ IP/ UnB.

** Docente na Universidade de Brasília. Professora e pesquisadora do Instituto de Psicologia da UnB PED/PGPDE e no Programa de Pós Graduação em Direitos Humanos e Cidadania - CEAM/UnB.
}

Este artigo de revista Estudos e Pesquisas em Psicologia é licenciado sob uma Licença Creative Commons Atribuição-Não Comercial 3.0 Não Adaptada. 